\title{
Double V-Y Flaps for Post Burn Contracted Neck
}

\author{
EMAN NAGY MOHAMED, M.D. and AHMAD EL-SHAHAT, M.D.
}

The Department of Plastic Surgery, Faculty of Medicine, Ain Shams University

\begin{abstract}
Background: Several techniques have been defined to be used in surgical treatment of post burn contracted neck. But, there were many problems with those techniques, like failure of graft take and postoperative contracture of the graft. The commonest problem in those techniques was distal flap necrosis which is frequently seen. As most of these techniques were based on random-pattern flaps and there is usually a poor blood supply to the scar tissue. But, here in this study, we can benefit from expansion in the distal part of the upper chest and lower neck caused by continuous traction of the contracted band which leads to expansion of the surrounding tissue with excess skin.
\end{abstract}

Aim of the Study: In this study, we aim to shift the excess tissue resulted from tissue expansion caused by traction of the contracture band from the base of the neck and upper chest to the upper neck by "double V-Y flaps" with direct closure of the donor site.

Patients and Methods: 17 patients with post burn scarring of the neck were included in this study. 11 females and 6 males with average age 20 (9-32) years old. 9 patients with double linear contracture and 8 patients with band contracture. Release of post burn scarring of the neck by "double V-Y flaps" was done, the excess tissue of the flap was used and direct closure of the donor site was done.

Results: The postoperative results represent the success of this technique in the surgical treatment of post burn scar contractures of the neck. All patients had an uneventful postoperative period with no distal flap necrosis. There was postoperative wound disruption in one patient that was managed by secondary sutures. The post burn scarring was successfully managed with this surgical technique "double V-Y flaps", with no major postoperative complications. One year follow-up period revealed no recurrence of the contracted bands.

Conclusion: "Double V-Y flaps" is a good technique in surgical treatment of post burn contracted neck with double linear or band contracture lines. This technique offers the patient a good chance for release of post burn contracted neck with no need to use graft or to wear postoperative neck collar.

Key Words: Double V-Y flap - Post burn scar-Contracture - Neck-Expansion.

\section{INTRODUCTION}

Morbidity of post burn contracted neck in the form of hypertrophic scars and contractures which are a common sequelae after burns remains high and their management represents a challenge, as more severely burned patients are surviving. Post burn contracted neck is significantly causing both functional limitations and aesthetic disfigurements of the patients. It is not only affecting the movements of the neck, but also had a great influence on the function of the lower face. So, the goal in management of those patients is to restore the function and the cosmetic appearance [1].

The burn scar contracture causes traction forces that could pull and results in insufficient neck extension, cicatricial ectropion, incomplete oral occlusion, distortion of the cervical spine and it might progress to tracheal alteration ending in difficult intubation. Such condition could be lifethreatening and cause severe complications necessitating surgical correction $[2,3]$.

The impact of these contractures has both economic and psychological aspects as it results in both cosmetic and functional issues. Especially in children, surgical correction is preferred as it might result in growth imbalance in the head and neck area $[3,4]$.

Aesthetic reasons alone would place cervicofacial contractures as a priority for reconstruction [5-10]. Surgical intervention mainly aims at releasing of the scar, restoring of appearance, natural profile and cervical movements and preventing recurrence [1].

Post burn contractures of the neck are classified according to the functional defect and the anatomical type of scar. According to the degree of con- 
tracture it is classified into mild, moderate and severe. Also, according to the type of the scar into linear, band or broad type [11].

In this study, we are following the rule of "Borrow from Peter to pay Paul only when Peter can afford it" Gillies and Millard quote; it means to shift the excess skin caused by expansion due to continuous traction of the band to the upper neck.

\section{Aim of the work:}

The aim of this study, is to use "double V-Y flaps" as an alternative to other surgical techniques in treatment of post burn contracted neck. In this technique, we aim to shift the excess tissue resulted from continuous traction of the contracture band on the surrounding tissue, to the upper neck in order to release the contracture with direct closure of the donor site.

\section{PATIENTS AND METHODS}

In this study, 17 patients with post burn contracted neck were included. 11 females and 6 males with average age 20 (9-32) years old. Patients with moderate degree contracted neck and double linear scar or band contracture were selected. 9 patients with double linear contractures and 8 patients with band contracture. This study was conducted during the period between February 2016 and April 2017 in Ain Shams university hospitals. Release of post burn contracted neck by "double V-Y flaps" was done, the excess tissue of the flaps was used and direct closure of the donor site was done.

Patients were selected according to inclusion criteria: (Cases of post burn neck with moderate degree contracture in the form of double linear or contracture band, both males \& females and $\mathrm{Pa}-$ tients with age group 9-32 were included). 12 patients were affected by scald burns while 5 patients were affected by flame burns.

On the other hand, the exclusion criteria were: (Patients who had previous release of contracted neck with failure of the graft take or postoperative re-contracture at the exact site of the graft, Infected cases of post burn neck contracture, Patients who develop sinus and fistula over neck contracture and patients with mild or severe contracture degree in the form of either single linear or broad band neck contracture type).

The limitation in patients with severe type of contracted neck in the form of "frozen neck" is that, there is no bands, so there is no expansion of the surrounding skin.
Preoperative evaluation of the patient in the form of: Brief relevant history and details of the burn injury were taken as, the cause of burn, severity of contracture, duration taken to form the contracture and any previous surgical intervention, along with proper clinical examination.

Local examination of the neck includes: Type and extent of the contracture (linear or linear band), skin texture, color match and contour. The range of neck movement and assessment of neck extension were performed. Pinch test is used to assess the availability of excess skin, determination of the angles of the double V flap and to check for direct closure of the donor site.

In general, the choice of the technically most possible operation is according to the functional and aesthetic results that should be good and the post-operative risks for recurrent neck contractures should be low.

In this study, the excess skin which results from continuous traction of the contracted band is used and redistributed to release the contracture, by using "double V-Y flaps". Markings were set on the patients pre-operatively over the lines of contracture and proposed incisions, to assess the amount of required soft tissue coverage.

All patients were evaluated subjectively by patient satisfaction score (four-point scale: Excellent-poor), using a questionnaire assessing the patient satisfaction as regards (neck movements including "extension and rotation", skin appearance including "texture and color matching", occurrence of complications and cosmetic appearance).

Operative Technique: The size of the flap and the angles of the double $\mathrm{V}$ should be planned according to the pinch test, which determines both the excess tissue to be shifted to the upper neck and the double $\mathrm{V}$ angles. Incisions were designed in the form of double $\mathrm{V}$ shape on the contracture lines. The angles were adjusted according to the excess skin. According to the width of the contracture band, the double $\mathrm{V}$ could be designed close to each other as $\mathrm{W}$ without a space between the double $\mathrm{V}$ if there is a double linear bands as in (Fig. 1A) and the double $\mathrm{V}$ is separated by a space if there is a wide band as in (Fig. 1B). According to the pinch test, the amount of excess skin is estimated and the length of each V flap is adjusted. The direction of the apex of the double $\mathrm{V}$ should be designed oblique lateral and not vertical. 

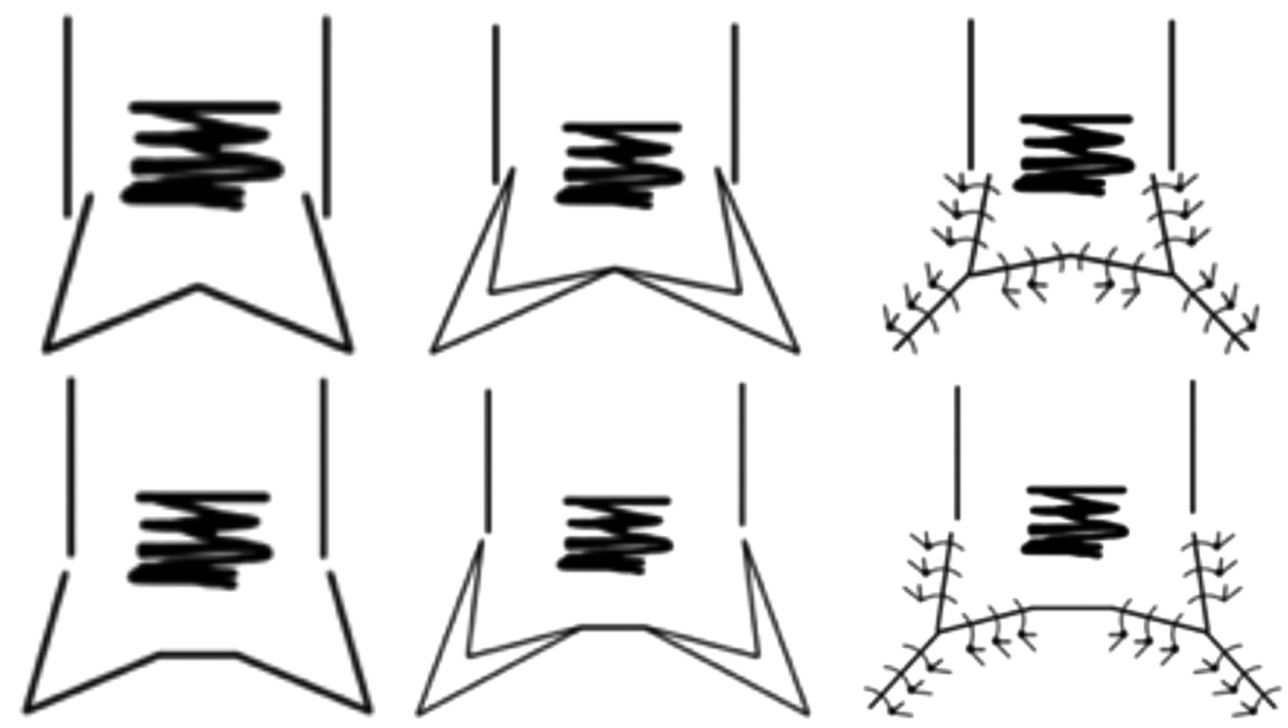

Fig. (1): Design of double V-Y flap, either, A (above): The double V are close to each other as W or B (below): Separated by skin bridge.

Release of the fibrotic bands was done and dissection through the scar to underlying normal tissue without undermining of the flaps till full extension was obtained and full release of the contracture bands. In this technique, the extra tissue of the double $\mathrm{V}$ is recruited from the surrounding expanded tissue. As, we are trying to redistribute the extra tissue to release the contracture.

Simple approximation of the incisions without excision of the excess tissue is done to the edges of the resultant defect. By doing this, the double $\mathrm{V}$ shaped incisions were transformed into a double Y-shaped with direct closure of the donor site.

Meticulous hemostasis and closure of the wound in layers using Vicryl 2/0 and 3/0 respectively. There was no need to use a suction drain as the dissection was minimal and with no undermining.

In the postoperative period, the Patients were nursed in supine position and the flaps were monitored as regards its temperature, color and capillary filling. Physiotherapy was started in the early postoperative period. The postoperative hospital stay was short in comparison to other techniques.

On discharge, the range of movement and condition of the flaps were noticed. No need for post-operative neck collar. Instructions regarding position, local care and physiotherapy were given. The patient was then asked to come for follow-up in the outpatient clinic regularly.

Evaluation of the results during this period was done regarding the general cosmetic appearance i.e. flap texture, color match, donor site morbidity and maintenance of contour, assessment of which was done during the follow-up period.

\section{RESULTS}

In this study, 17 patients with post burn contracted neck were treated by release of the contracted neck by "double V-Y flaps". All cases had improvement of the neck extension with release of the contracted bands. Patient satisfaction as regards both aesthetic and functional aspects was noticed in all patients.

The operation time ranged from 30 minutes to one hour with average 40 minutes for all cases. The postoperative results represent the success of this technique in the surgical treatment of post burn scar contractures of the neck. All patients had an uneventful postoperative period with no distal flap necrosis.

Whereas, there was postoperative wound disruption which was managed by secondary sutures. The post burn scarring was successfully managed with this surgical technique "double V-Y flaps", with no major postoperative complications. One year follow-up period revealed no recurrence of the contracture bands.

Postoperative evaluation of all patients as regards range of neck extension, overall cosmetic appearance were satisfactory with no donor site morbidity (Figs. 2,3).

The overall patient satisfaction score was in the form of " 10 patients (excellent), 4 patients (good), 2 patients (satisfactory), and 1 patient (poor) (Fig. 4). 

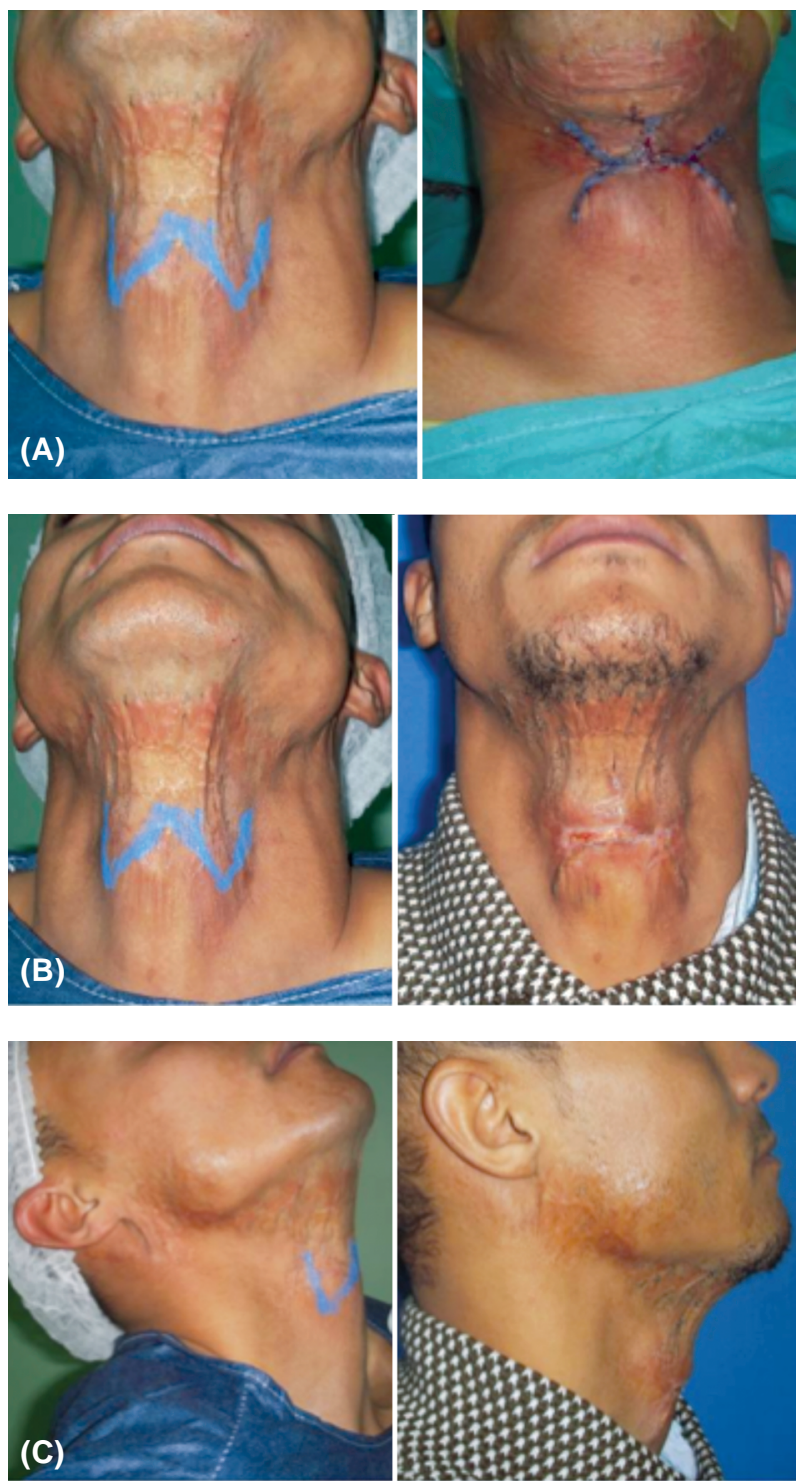

Fig. (2): A 24-years-old male patient with post burn neck contracture. (A): A design of double V-Y flaps (the $\mathrm{V}$ flaps are designed close to each other as W). (B): All incisions were closed primarily in the form of Y. (C): Satisfactory results were obtained 3 months later in both front and lateral views both functionally and cosmetically.

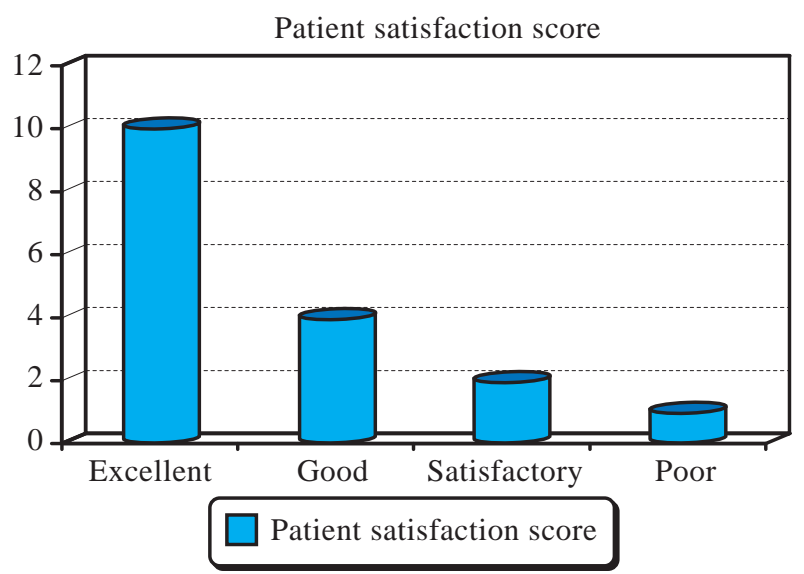

Fig. (4): Shows patient satisfaction score in group.
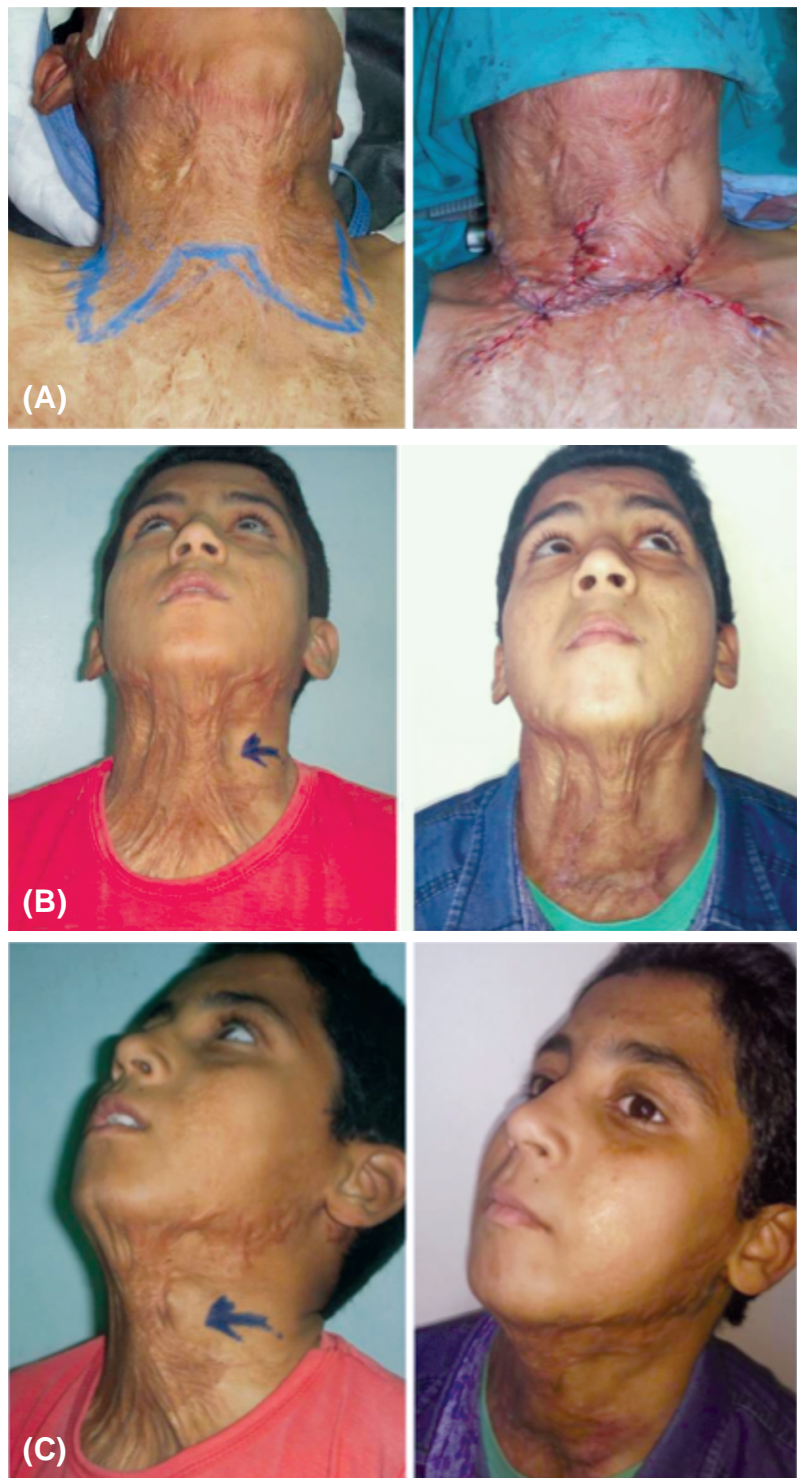

Fig. (3): A 13-year-old male patient with post burn neck contracture. (A): A design of double $\mathrm{V}$ double $\mathrm{Y}$ flaps (the double $\mathrm{V}$ is separated by a space), (B): All incisions were primarily closed in the form of Y. (C): An acceptable result was obtained functionally and cosmetically 3 months later both front and lateral views.

\section{DISCUSSION}

The anterior cervical region is vulnerable to be affected mostly in burns. However, Contractures and hypertrophic scars represent a common annoying sequel post neck burn and these scars are commonly severe. As the skin in this area is loose, thin and easily affected. In addition to that, the area from the chin to the sternum is a concave flexor surface. Being extremely mobile makes the neck more liable to contracture formation. Lastly, contracted scar bands are more prone to occur following any vertical incisions in the skin of the 
anterior cervical area, being accidental or surgical [1].

The most important point in these burn contractures is not only that those patients are functionally demanding, but they are also cosmetically suffering. Successful reconstructive surgery can result in a happy and productive life. The key to successful reconstruction of post burn neck contracture is to know, understand, appreciate and favorably influence the process of wound healing \& scar maturation. Usually this is achieved by proper choice of the surgical technique that is both functionally and aesthetically effective with the least donor site morbidity. Many surgical techniques were described starting from release and application of STSG to free flaps [1].

Skin grafting is considered a basic, safe and dependable operation. Unfortunately, it could cause hypertrophy and recurrence of contracture. In case of local and regionals flaps, reconstruction with a good color and texture match is most likely obtained. However, it might not be possible in cases of severe scarring affecting the surrounding tissues or due to random pattern flaps or the deficient blood supply of the scar tissue resulting in distal flap necrosis [1].

As we were taught from the principles of plastic surgery and from our professors, that linear scar expands the surrounding skin due to continuous traction. We can break this scar by Z-plasty that includes redistribution of the surrounding excess skin. Based on this principle we use "double V-Y flaps".

Ernst Blasius was probably the first to describe the V-Y-plasty when he used V-Y flaps for correction of post burn contracted neck [12].

In our study, careful planning of "double V-Y flaps" require the use of the excess tissue. As, the extra tissue is recruited to support the V flap. Thus, it was advanced on each sides of post burn scar contracture.

In cases of linear post-burn scar contractures, correction is usually done using a Z-plasty or a VY-plasty or any of their analogues. However, Suzuki et al., used subcutaneous pedicle flaps instead for such corrections. In their study, only one partial flap necrosis was reported among 17 subcutaneous pedicle flaps [13,14].

However, the challenge remains to be when we are going for release of wide contractures, as necrosis of the distal flaps is not uncommon. This could result from dissecting flaps of scar tissue, due to the poor vascularity of the contracture site scar as the circulation in those flaps have random patterns. Whereas, in "double V-Y flaps", risk of distal flap necrosis is unlikely as there is no undermining of flaps to close primarily.

In our study, the "double V-Y flaps" have a subcutaneous pedicle which has some leverage to other random-pattern skin flaps regarding flap viability, mobility and easy design. Designed flaps should contain subcutaneous tissue as it is most likely to be intact below the post burn scars.

In his study, Suzuki suggested safe rotation of the subcutaneous pedicle flaps up to $90^{\circ}$ and even stretched over the distance of the flap size yet it risks distal flap necrosis. When the flap didn't reach the planned area, deeper dissection and conservative narrowing of pedicle was done [14]. So, the subcutaneous pedicle flap needs careful undermining and dissection of the subcutaneous tissue to reach a $100 \%$ gain but it is not $100 \%$ safe.

In our study, there is no rotation of flap, no undermining or deeper dissection and the angle of the $\mathrm{V}$ flap is adjusted according to the amount of excess skin. So, the risk of skin necrosis is decreased. It may not give a $100 \%$ gain but, it is a $100 \%$ safe technique. The "double V-Y flaps" is safer than other subcutaneous pedicle flaps.

In order to preserve the perforating vessels, mindful dissection of the subcutaneous pedicle flaps in mandatory. So, a magnifying loupe may be needed during dissection [14]. But, in "double V-Y" flaps, such dissection is not needed or done. So, "double V-Y flaps" is a good choice for some junior surgeons, as there is no pedicle dissection nor the risk of distal flap necrosis.

The double V-Y plasty requires less incisions, requires a shorter down time of the operation and shorter hospital stay with no donor site morbidity in comparison to other techniques. So, "Double VY flaps" is advised as, it is easy to use with color and texture matching that are acceptable.

\section{Conclusion:}

Post-operative neck function is as essential as the cosmetic appearance. So, "Double V-Y flaps" is a good technique in surgical treatment of post burn contracted neck with double linear or band contracture lines. As it offers the patient a good chance for release of post burn contracted neck with no need to use graft or to wear postoperative neck collar. 


\section{REFERENCES}

1- Nikunj Bhavesh Mody, Sanket S. Bankar and Avinash Patil: Post Burn Contracture Neck: Clinical Profile and Management. J. Clin. Diagn. Res. Oct., 8 (10), 2014.

2- Laredo Ortiz C., Valverde Carrasco A., Novo Torres A., Navarro Sempere L. and Márquez Mendoza M.: Supraclavicular bilobed fasciocutaneous flap for postburn cervical contractures. Burns, 33: 770-5, 2007.

3- B.M. Achauer: New York: Thieme Medical Publishers. Neck reconstruction. In: Achauer B.M., editor. Burn Reconstruction, pp. 79-86, 1991.

4- Pallua N., Künsebeck H.W. and Noah E.M.: Psychosocial adjustments 5 years after burn injury. Burns, 29: 143-52, 2003.

5- Edlich R.F., Nichter L.S., Morgan R.F., Persing J.A., Van Meter C.H. Jr. and Kenney J.G.: Burns of the head and neck. Otolaryngol. Clin. North Am., 17: 361-88, 1984.

6- Kobus K. and Stepniewsky J.: Surgery of post-burn neck contractures. Eur. J. Plast. Surg., 11: 126-8, 1988.

7- Voinchet V., Bardot J., Echinard C., Aubert J.P. and Magalon G.: Advantages of early burn excision and grafting in the treatment of burn injuries of the anterior cervical region. Burns, 21: 143-6, 1995.

8- Iwuagwu F.C., Wilson D. and Bailie F.: The use of skin grafts in postburn contracture release: A 10-year review. Plast. Reconstr. Surg., 103: 1198-204, 1999.

9- Feldman J.J.: Reconstruction of the burned face in children. In: Serafin D., Georgiade N.G., editors. Pediatric Plastic Surgery. Vol. 1. St. Louis: Mosby, 1984.

10- Fernández-Palacios J., Baeta Bayón P., Cubas Sánchez O. and García Duque O.: Multilevel release of an extended postburn contracture. Burns, 28: 490-3, 2002.

11- Makboul M. and El-Oteify M.: Classification of post burn contracture neck . Indian J., 21 (1): 50-54, 2013.

12- Hauben D.J.: Ernst Blasius's contributions to plastic surgery. Plast. Reconstr. Surg., 74: 561-70, 1984.

13- Suzuki S., Matsuda K. and Nishimura Y.: Proposal for a new comprehensive classification of V-Y-plasty and its analogues: the pros and cons of inverted versus ordinary Burow's triangle excision. Plast. Reconstr. Surg., 98: 1016-22, 1996.

14- Suzuki S., Isshiki N., Ishikawa K. and Ogawa Y.: The use of subcutaneous pedicle flaps in the treatment of postburn scar contractures. Plast. Reconstr. Surg., 80: 792-8, 1987. 